\title{
Future Intelligent Civil Structures: Challenges and Opportunities
}

\author{
J. C. Li, Y. Li, M. Askari and Q. P. Ha \\ Centre for Built Infrastructure Research, University of Technology Sydney, Australia \\ E-mail: Jianchun.li@uts.edu.au, \\ Yancheng.li@uts.edu.au, Mohsen.askari@uts.edu.au
}

\begin{abstract}
-
An intelligent civil structure offers ultimate protection to its structure, contents and occupants in terms of safety and functionality against undesired dynamic loadings and structural deficiency. In this paper, the concept of the future intelligent civil structure featuring self-adaptive, selfprognostic, self-sensing, self-powering and self-repairing abilities, is proposed. A decade research efforts from Centre for Built Infrastructure Research, University of Technology Sydney, towards the development and concept proof of such intelligent structure is reviewed.
\end{abstract}

\section{Keywords -}

Intelligent civil structures; Structural control, Structural health monitoring, Self-adaptive; Self-prognostic; Selfsensing; Self-powering; Self-repairing;

\section{Introduction}

Emerging from recent advance in smart material technology, advanced sensing, signal processing and advanced control theory, intelligent civil structures potentially offer ultimate protection to the civil structures as well as their contents and occupants in terms of safety and functionality against undesired dynamic loadings and damage or structural deficiency. Intelligent structure related research and development, therefore, possess enormous theoretical and practical values and thus are becoming a rapidly emerging area of research recently [1-2].

An intelligent civil structure can be defined as a structural system with a higher-level of autonomy. Such intelligent structures rely on the embedded functions of sensors, actuators and micro-processors with optimizations and integrated structural control algorithms that can automatically adjust structural characteristics to optimally adapt to external disturbance and environmental changes. Thus, structural safety and serviceability as well as the prolongation of structural service life are assured [2].

There have been many research and development in the field to develop smart civil structures. Benefiting from recent advances in smart materials, i.e. piezoelectric material[3-4], shape memory alloy, electro-sensitive materials and magneto-sensitive materials[5-8], vaious smart materials have been utilised in development of smart devices to facilitate semi-active/active structural control. Adaptive structural control of civil structures forms critical component for the development of intelligent civil structures.

In this paper, after a brief review on the recent development on intelligent civil structure research, the authors will present a new concept of intelligent civil structure with " $5 \mathrm{~S}$ " features. An introduction on the testing facilities available in Centre for Built Infrastructure Research (CBIR) will be given and the research activities in CBIR toward advancing intelligent civil structure research will then be reported. At the end of the paper, research activities to be carried out in next stage are also highlighted.

\section{Future Intelligent Civil Structure Research}

An intelligent civil structure of the future should possess the following characteristics: optimally respond to a changes of both external and internal environment (selfadaptive); instantly and reliably detect structural change or damage and evaluate their impacts (self-prognostic); automatically sense and collect information of structural members (self-sensing); be independent from external power sources for the required operations (self-powering); utilizing various means in real-time to minimise impact of damage and restore structural load carrying capacity (selfrepairing). These $5 \mathrm{~S}$ features of an intelligent structure represent authors' definition of true intelligent civil structures and impose a series of challenges to the field of research. The challenges may be described as followings:

- Design and development of smart structural members that can be integrated as a part of the structure;

- Embedment of energy harvesting into smart structure design to provide independent power supply for the smart structure system;

- utilisation and integration of sensing ability of smart materials to accomplish self-sensing ability;

- Optimization of numbers and locations of smart structural members in the structure;

- Online and real-time identification of structural characteristics after either graduate or sudden changes.

- Developing novel algorithm to integrate and optimise structural control and structural monitoring;

- When structural damage occurs, utilizing controllability of smart structural members to alter 
loading path in to minimize damage effects and further damage;

- Experimentally realize and evaluate $5 \mathrm{~S}$ intelligent civil structure in laboratories.

\section{Research Facilities at Centre for Built Infrastructure Research}

\subsection{UTS Shake Table}

The UTS shake table has been established from two consecutive infrastructural funding from Australian Research Council after 1989 Newcastle earthquake, which is aimed at encouraging earthquake engineering research in Australia. Designed by a well-known test equipment manufacturer, MTS from USA, it was established in the Structure Lab of UTS in 1995. This advanced testing facility is the only its kind within Australian universities. The self-weight of the shake table is 6 tones and it is capable of carrying a payload up to 10 tonnes. The maximum horizontal displacement is $\pm 100 \mathrm{~mm}$ and the maximum acceleration for the bare table is $2.5 \mathrm{~g}$. With advanced hydraulic system and control system, this shake table can simulate any vibration sources in the range of $0.1 \mathrm{~Hz}$ to $100 \mathrm{~Hz}$. For earthquake engineering research, the four benchmark earthquakes, i.e. 1940 El-Centro, the 1968 Hachinohe, the 1994 Northridge, and the 1995 Kobe earthquake records can be produce by the shake table.

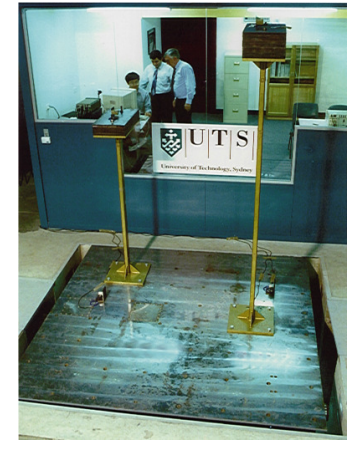

Figure 1. UTS shake table

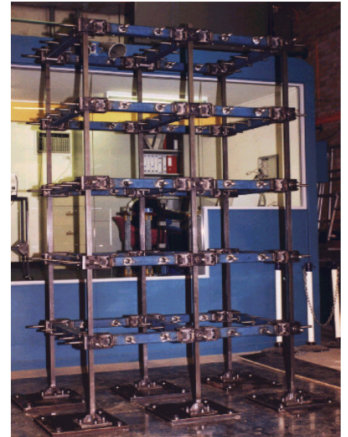

Figure 2. International 5Storey Benchmark Building Model

\subsection{International 5-Storey Benchmark Building Model}

In 1990s under auspices of the International Association of Structural Control and Monitoring, a 5storey international benchmark building model was designed and manufactured in UTS. The facility has been adopted by the community for encouraging international collaborative research in the area of vibration control of building structures. The model has a height of $3 \mathrm{~m}$ and five adjustable story units with typical story height of $0.6 \mathrm{~m}$. the mode has a footprint of $1.5 \mathrm{~m} \times 1.0 \mathrm{~m}$. It consists of two bays in one direction and a single bay in other direction. The mass of the building model can vary between 1 tonne to 3.5 tonnes. The joint connections of the structure can be changed between fixed and pinned. The building height can also be modified by the innovative connection design.

\section{Intelligent Civil Structure Research at Centre for Built Infrastructure Research}

In developing future $5 \mathrm{~S}$ intelligent civil structures the critical issues to be explored are: 1) design and characterization of smart structural members; 2) development of control algorithm for self-adaptive ability for intelligent structures; 3) development of energy harvesting unit for self-powering and self-sensing; 4) integration of structural control and structural health monitoring for self-prognostics and self-repairing. To date, Centre for Built Infrastructure Research has made progress in advancing each of the critical technology individually. Future research in integration of the system to create an ultimate intelligent civil structure with $5 \mathrm{~S}$ features will be carried out in the future work.

\subsection{Development of Semi-Active Structural Members 4.1.1 Smart Pin-Joint using Magnetorheological Fluids}

In the types of beam-column structures, type of joint connections, i.e. fixed and pinned connections, affect stiffness of the structure. A fully controllable beamcolumn connection joint allows civil structures to alter its stiffness matrix adaptively in a wide range thus achieve structural control [9-10]]. Such concept was firstly proposed by UTS researchers [9]. The research aimed to design and develop a variable smart pin-joint by utilizing a magnetic sensitive material, i.e. magnetorheological fluids (MR fluids). MR fluids possess reversible, controllable and real-time viscous property when subjected to external magnetic field. With an electromagnetic coil to provide varying magnetic field, a smart pin-joint was capable of producing controllable moment resistance in a range of less than $1 \mathrm{Nm}$ to $30 \mathrm{Nm}$. Steady rotational testing [11-12] and dynamic cycling testing [13-14], shown in figure 4, were conducted using experimental setups shown in Figure 3. Theoretical evaluation [15] and hysteresis modelling [13-14] were carried out to characterise the performance of the MR pin-joint. In the next stage work, the smart pin-joint will be installed in a two-story building model for applications on structural control and online system identification.
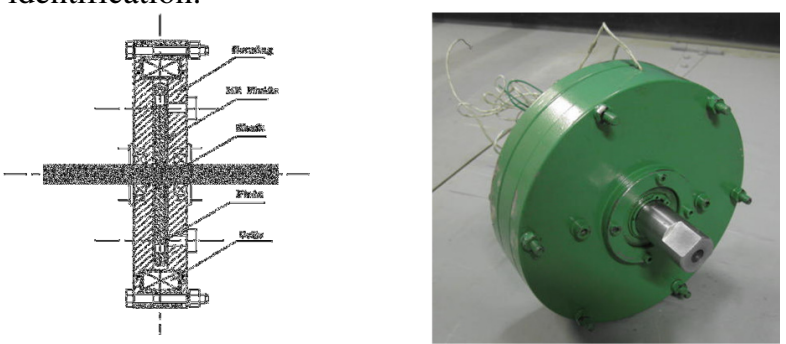

Figure 3. MR pin joint: (1) cross-section; (2) prototype 

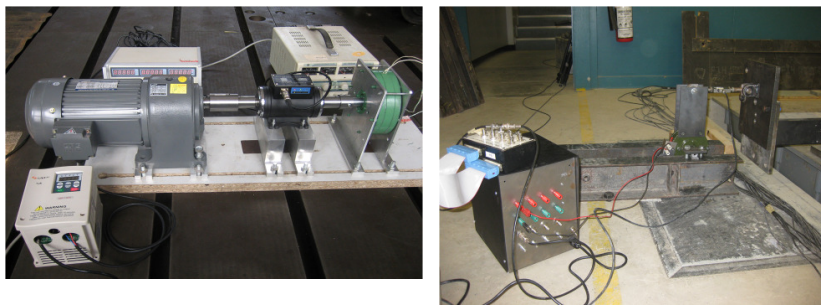

Figure 4. experimental testing: (1) steady testing; (2) dynamic testing

\subsubsection{Adaptive Magnetorheological Elastomer Base Isolator}

As most important means in seismic protection of civil structures, base isolation is used to decouple superstructure from damaging ground motion, i.e. earthquakes, by installing isolation layers between them. Recently, base isolation systems encountered their challenges for its incapability in adapting versatile earthquakes due to its passive nature. This research proposed a novel adaptive base isolator utilising magnetorheological elastomer (MR elastomer). Similar as MR fluids, MR elastomer can change its material property, i.e. shear modulus, when external magnetic field is applied. The proposed adaptive base isolator, inheriting critical laminated design, possesses large compressive stiffness with controllable lateral stiffness [16-21], shown in figure 5. Two prototypes of MRE adaptive isolators, i.e. with 37 MRE layers ( $2 \mathrm{~mm}$ thick each) and 25 MRE layers (1 $\mathrm{mm}$ thick each), have been fabricated and tested (Figure 6). the experimental results revealed that they can induce stiffness increase of $37 \%$ [17] and 1630\% [21], respectively, as shown in Figures 7-8. To characterise the behaviours of the devices, different hysteresis models, i.e. Bouc-Wen model [22] and Strain-stiffening model [23], have been proposed. Large scale experimental testing will be conducted in late 2014 and early 2015 to prototype smart base isolation system utilizing UTS shake table and international 5story benchmark building model. This research already won several awards in Australia, including $1^{\text {st }}$ prize in UTS Uniquest Trailblazer and $3^{\text {rd }}$ prize in National Grand Final of Research and Innovation by Uniquest. Intellectual property on magnetic field generation for multiple MRE layers is protected by Australian PCT patent [24].

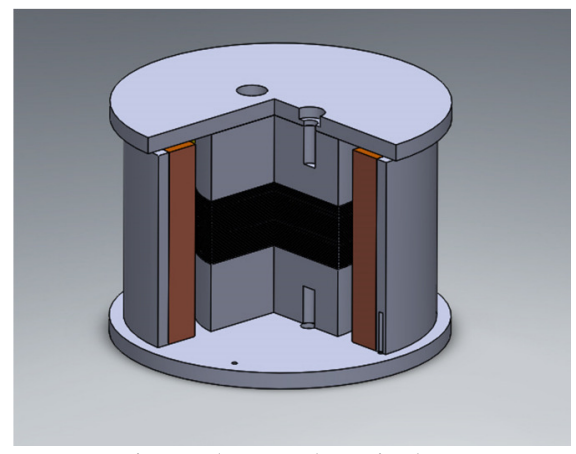

Figure 5. MRE base isolator

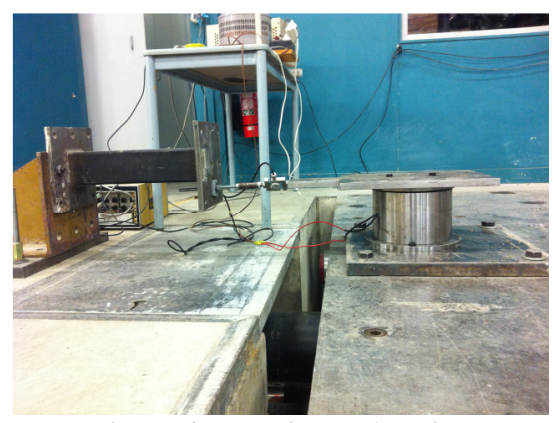

Figure 6. Experimental testing

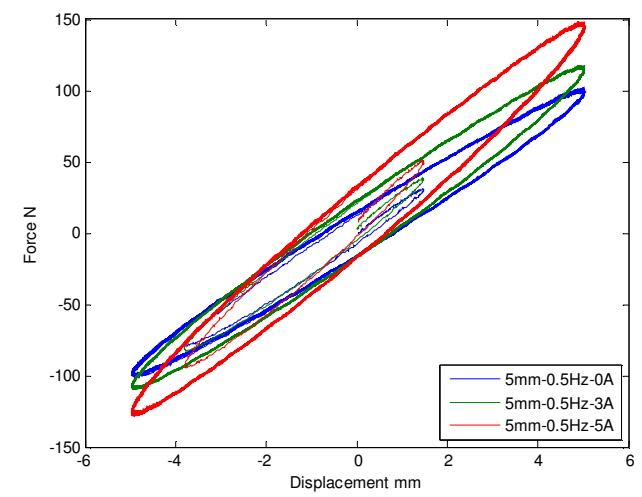

Figure 7. Force vs displacement of $1^{\text {st }}$ prototype

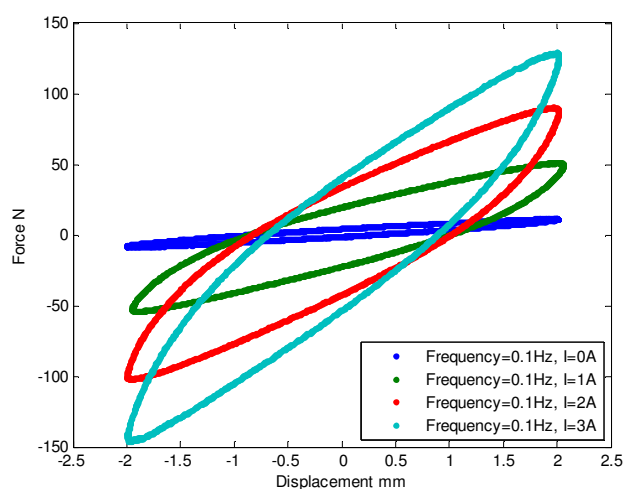

Figure 8. Force vs displacement of $2^{\text {nd }}$ prototype

\subsection{Energy Harvesting Technology for Self-Sensing and Self-Powering Ability}

Scavenging energy from vibrations, known as energy harvesting, is an emerging technology of alternative energy solution in engineering fields. It can be used to power the sensors in the structural health monitoring systems as well as provide power for semiactive control devices. Due to the intrinsic relationship between the harvested energy and external vibration, it can be also used as means to collect dynamic information on external environment. Thus, development of energy harvesting units is the key towards realization of self-powering and self-sensing abilities.

\subsubsection{Energy Harvesting Device using Piezoelectric Material}

This project focuses on the development and testing of energy harvesting unit using piezoelectric material. A compression-based piezoelectric energy harvester using a multilayer stack configuration, shown in Figure 9, is designed and tested in Centre for Built Infrastructure 
Research. The stack configuration makes this design suitable for environment with large compressive force and small deformation. In this research, theoretical analysis is explored to evaluate its capacity [25]. Dynamic testing (figure 10) was conducted to find the relationship between the harvested energy and external loadings [25-26]. The experimental results show that the proposed piezoelectric stack harvester can generate up to $200 \mathrm{~mW}$ electrical power under harmonic excitation. Linear relationship was found between the harvested power and the external vibrations [26].

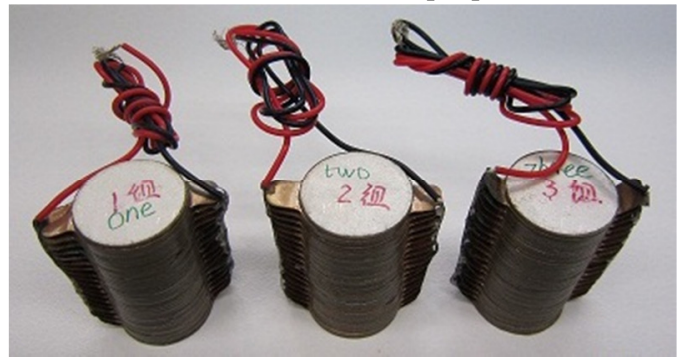

Figure 9. PZT stack harvester

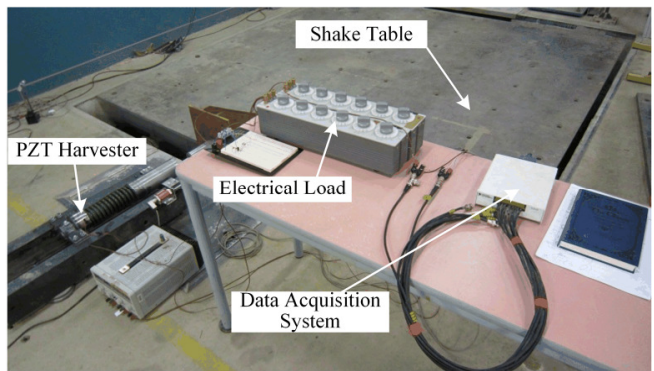

Figure 10. Experimental testing

\subsubsection{Energy Harvesting Device using Electromagnetic Induction}

This project addresses the development of energy harvesting unit utilizing electromagnetic induction (EMI) The principle of this design is to allow moving permanent magnets to pass through the magnetic field induced by electromagnetic coils. Detailed design is shown in Figure 11. In [27] and [28], detailed design is introduced on the two-phase EMI energy harvester. Theoretical analysis was conducted to find the relationship between harvested energy and external vibration. Further experimental evaluation is to be conducted to verify the theoretical findings.

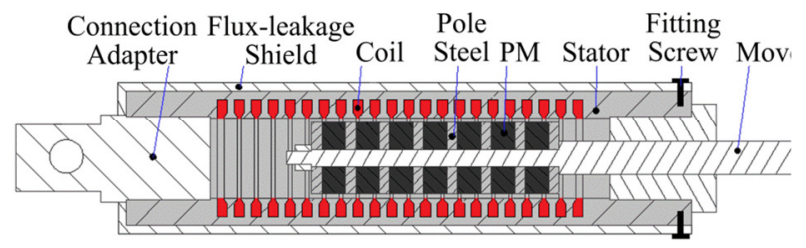

Figure 11. Cross-section view of EMI energy harvester

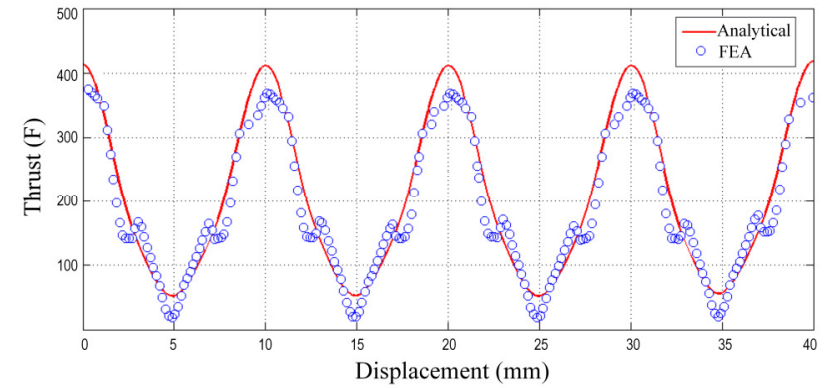

Figure 12. Numerical simulation and finite element analysis

\subsection{Multi-Objective Optimal Placement of Structural Control Devices}

The optimal design and placement of control devices, is an important problem that affects the control of civil engineering structures. According to literature, most of the reported works in this area have focused on optimal assignments of active control devices with one or two structural indices as the objective functions to be minimized through the optimization process [29]. However, it is necessary to do a comparative study between optimal locations of actuators and MR dampers and show the differences. Moreover, since optimal placement of control devices in a structure deals with integer adjustable parameters (each actuator/damper can be assigned to an integer value which is the floor number), an advanced and accurate integer coded optimization algorithm is needed. In addition, a set of Pareto fronts, as the final result of optimization, gives more flexibility to the user to choose one's own design based on one's own criteria.

To this end, a modified integer coded version of nondominated sorting genetic algorithm II (MI-NSGAII) was introduced in this research study and applied to find optimal places of actuators and MR dampers in a nonlinear 20-storey benchmark building [30], shown in Figures 13-14.. The method uses the best features of a recently developed integer coded algorithm named MILXPM into the framework of NSGAII. Using the proposed approach, a Pareto front can be generated using three considered objective indices, i.e. peak inter-storey drift ratio $(\mathrm{J} 1)$, peak acceleration $(\mathrm{J} 2)$ and peak base shear force (J3). The results of optimal placement of active actuators were compared to the benchmark problem definition in which 25 actuators have been located in non-optimal locations. Results showed the effect of proposed strategy where the same level of structural pcrformance, in terms of proposed objective functions, was obtained by use of only 7 actuators in an optimal layout [31], shown in Figure 15.
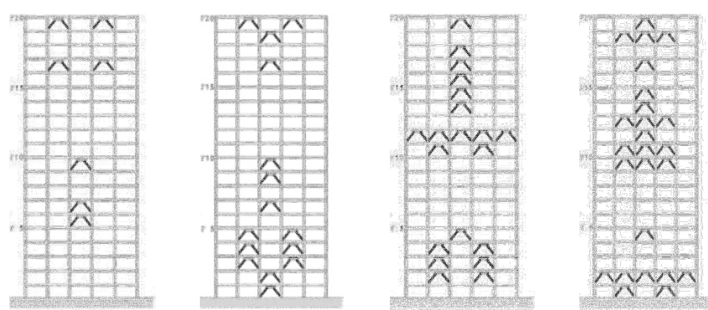

Figure 13. Optimal places of different number of actuators respect to $J_{1}, J_{2}$ and $J_{3}$. 

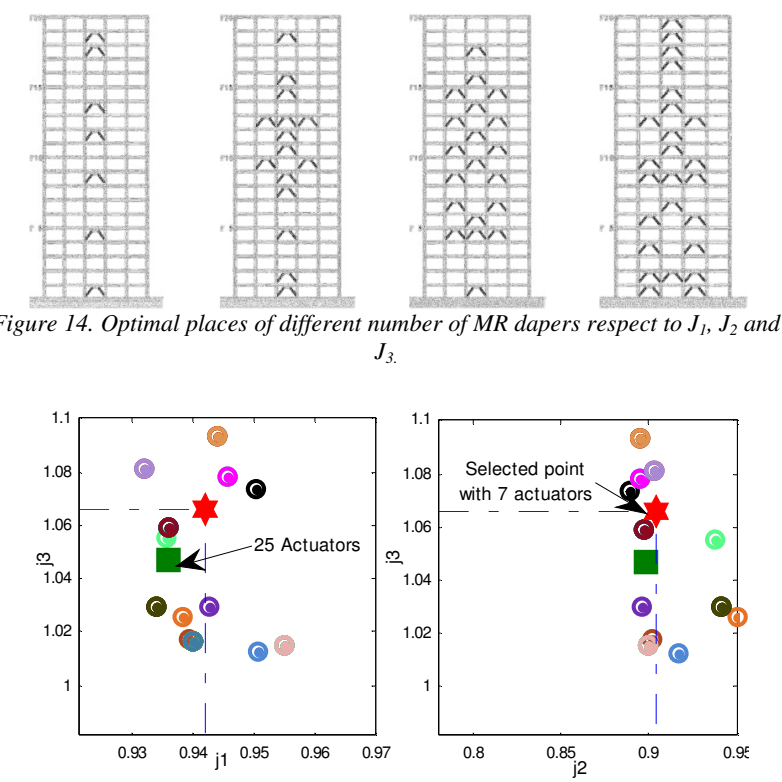

Figure 15. Pareto Fronts Obtained for Optimal Placement of 7 actuators

\subsection{Semi-Active Control of MR Dampers for Self- Adaptive}

One of the challenges in the application of MR dampers is using an appropriate control algorithm to determine their command voltage[32]. Two essential steps for the development of semi-active control algorithms are: 1) development of appropriate hysteresis model for MR damper; and 2) evaluation of semi-active control algorithm for structural control.

This part of research aimed at addressing the aforementioned issues through numerical simulations and experimental testing. In the modeling of hysteresis of MR dampers, various models were proposed, i.e. Bouc-Wen model [33], Hyperbolic model [34], inverse model[30] and curve fitting technique [35]. Bouc-Wen model was modified based on classical Bouc-Wen model in which an evolutionary variable $\mathrm{z}$ is used to model the nonlinear hysteresis [32]. In the hyperbolic model, a hyperbolic function was used to describe the nonlinearity [33]. The inverse model is to model the inverse dynamics of MR damper using a novel multi-objective optimal subtractive Fuzzy C-Mean clustering technique[30]. In the development of control strategies, several control algorithms have been used, such as Sliding Mode Control[34], Lyapunov-Based Control[35], optimal LQG control[30] and direct control [36-38]. Figure 16 shows the applications of proposed controllers to a 20 -storey nonlinear building with 25 optimally placed MR dampers, illustrated that the proposed new control algorithms can effectively track the desired control force and perform much better than the original and modified versions of clipped optimal controllers (COC and MCOC) in terms of structural response reduction with less control force and power.

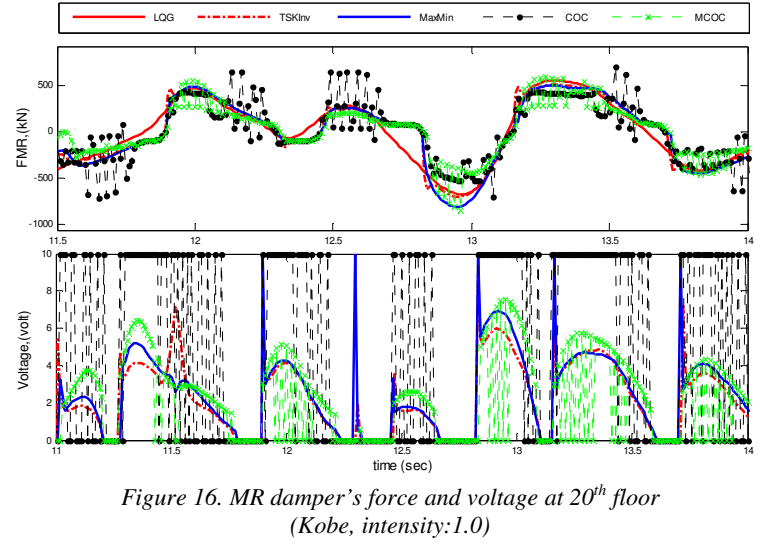

4.5 Online Real-Time Structural Identification for Self-Prognostics

Structural Identification and Damage prognosis is the prediction in near real time of the remaining useful life of an engineered system, given the measurement and assessment of its current structural state and accompanying predicted performance in anticipated future loading environments. An important objective of health monitoring systems for civil infrastructures is to identify the state of the structure and to evaluate its possible damage[39]. Frequently, damage can be inferred from the changes of structural parameters, such as the stiffness and damping coefficients.

This project focuses on online real-time structural identification [40] to acquire the status of the structures. Several real-time identification methods, i.e. Kalman filter, Extended Kalman Filter (EKF), iterated Extended Kalman Filter (IEKF) have been studies and results found that these methods are not effective in the case of highly nonlinear problems. To overcome the problem, two filtering techniques, namely, unscented Kalman filter (UKF) and iterated unscented Kalman filter (IUKF), have been recently developed to handle any functional nonlinearity. Comparative study was also carried out on the aforementioned methods for their effectiveness and efficiencies through a highly nonlinear SDOF structure as well as a two-storey linear structure.

The Recursive Least Square (RLS) based methods are also another category of identification approaches which have been used widely in estimation of structural system parameters. In this research [41-42], a new adaptive tracking technique, based on RLS with adaptive multiple forgetting factors (AMFF-RLS), was presented which can estimate the unknown structural parameters as well as unknown input, e.g. earthquake signal. The method was applied to different structures, with different excitations and damage scenarios. It is found from the results that the proposed algorithm can effectively identify the time-varying parameters such as damping, stiffness, as well as unknown excitations with high computational efficiency, even when the observed data were contaminated with different types and significant levels of noise[43]. 

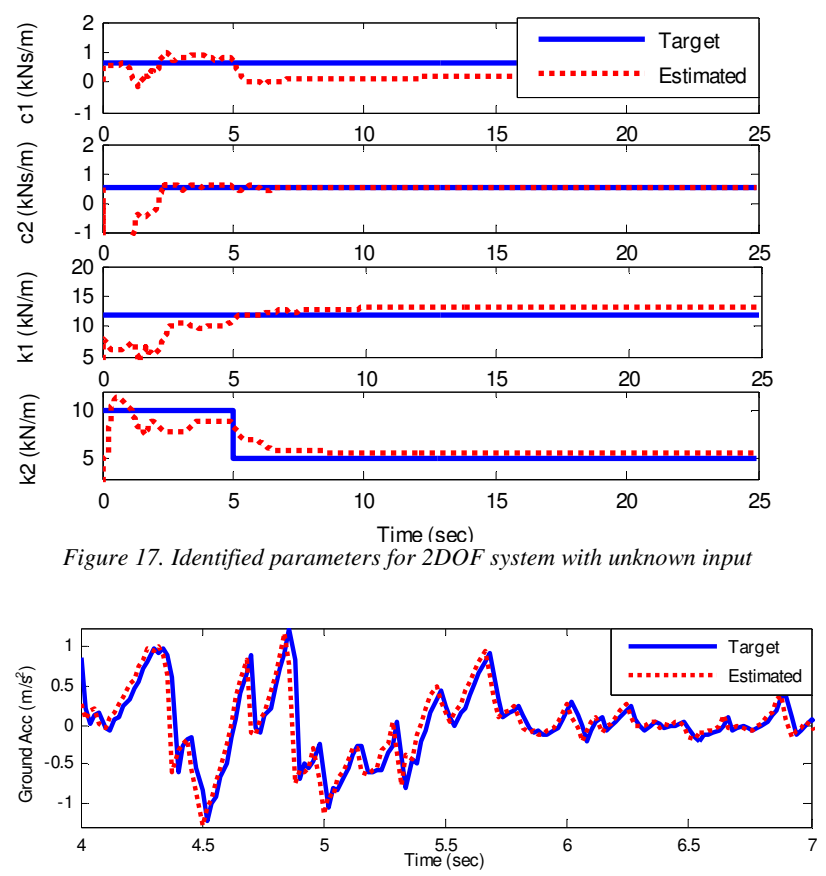

Figure 18. Identified unknown earthquake acceleration for the 2DOF system

\section{Conclusions}

Intelligent civil structure represents an emerging research trend in the field for protection of civil structures against undesired motions and disturbances. Centre for Built Infrastructure Research at UTS has embraced this new concept of the intelligent civil structures by conducting a series research on concept proof of Self-adaptive, Self-prognostic, Self-sensing, Self-powering and Self-repairing abilities of the intelligent civil structures. This paper provides a brief report on these activities and challenges in developing such intelligent structures. Further research towards integration and experimental evaluation of the intelligent civil structure has been planned and will be carried out soon.

\section{References}

[1] Soong, T.T. Active structural Control: Theory and Practice, Longman Scientific and Technical, Essex, England, 1990.

[2] Fujino, Y., Soong, T.T., and Spencer Jr., B.F., Structural Control: Basic Concepts and Applications, Proc. ASCE Structures Congress XIV, Chicago, Illinois, pp. 1277-1278, 1996.

[3] Chen B, Xu YL. Integrated vibration control and health monitoring of building structures using semiactive friction dampers: Part I-methodology. Engineering Structures, 30(7): 1789-1801, 2008.

[4] Chen B, Xu YL. Integrated vibration control and health monitoring of building structures using semiactive friction dampers: Part II-Numerical investigation. Engineering Structures. 30 (3):573587, 2008.

[5] Xu, Y.L., Qu, W.L. and J.M. Ko. Seismic response control of frame structures using magnetorheological/ electrorheological dampers. Earthquake Engineering and Structural Dynamics, 29(5):557-575, 2000.

[6] Qu, W.L. and Xu, Y.L. Semi-active control of seismic response of tall buildings with podium structures using ER/MR dampers. The Structural Design of Tall Buildings, 10(3):179-192 2001

[7] Chen, J., Xu, Y.L., Qu, W.L. and Ng, C.L. Seismic response control of a complex structure using multiple MR dampers: Experimental investigation. Journal of Earthquake Engineering and Engineering Vibration, 3(2):181-193, 2004

[8] Wang $\mathrm{J}$ and Li Y. Dynamic simulation and test verification of MR shock absorber under impact load. Journal of intelligent material systems and structures, 17 (4):309-314, 2006.

[9] Widjaja, J.H. \& Samali, B., Li, J. The use of Displacement Threshold for Switching Frequency Strategy for Structural Vibration Mitigation. Journal of Mechanical Science and Technology, June 2007, 21(6):865-869, 2007.

[10]J. Widjaja, B. Samali and J. Li. ER and MR Duct Flow in Shear-Flow Mode using Herschel-Bulkley Constitutive Model. ASCE Journal of Engineering Mechanics. 129(12):1459-1564, 2003.

[11] Li Y., Li J., Samali B., Wang J. Theoretical and experimental studies on semi-active smart pin joint. Proceeding of 20th Australasian Conference on the Mechanics of Structures and Materials, pages 723728, Toowoomba, Queensland, Australia, 2-5 December 2008,

[12] Li Y., Li J., Samali B., Wang J. Design considerations and experimental studies on semiactive smart pin joint. Frontier of Mechanical Engineering in China. 4(4):363-370, 2009.

[13] Li Y. and Li J., Dynamic characteristics of a magnetorheological pin joint for civil structures, Frontier of Mechanical Engineering, doi: 10.1007/s11465-014-0283-0, 2014

[14] Li Y., Li J. and Samali B. Dynamic performance of a novel magnetorheological pin joint, Journal of System Design and Dynamics, 5 (5):706-715,2011.

[15] Li Y., Li J. and Samali B., Design of new generation magnetorheological pins, 21st Australasian Conference on the Mechanics of Structures and Materials, pages 807-812, Victoria University (VU), Melbourne, Australia, 7-10 December, 2010,

[16] Li Y., Li J. and Samali B., On the magnetic field and temperature monitoring of a solenoid coil for a novel magnetorheological elastomer base isolator, Journal of Physics: Conference Series, 412(1):1-7. 2013,

[17] Li Y., Li J., Li W. and Samali B., Development and characterization of a magnetorheological elastomer based adaptive seismic isolator, Smart Materials and Structures. 22 (3): 035005, 2013.

[18] Li Y., Li J. and Samali B., A novel adaptive base isolator utilising magnetorheological elastomer', 22nd Australasian Conference on the Mechanics of Structures and Materials, Pages763-767,Sydney, Australia, 11-14 December, 2012.

[19] Li J., Li Y., Li W. and Samali B., Development of 
adaptive seismic isolators for ultimate seismic protection of civil structures', the SPIE 20th Annual International Symposium on Smart Structures and Materials + Nondestructive Evaluation and Health Monitoring, Town \& Country Resort and Convention Center, San Diego, California, United States (Paper ID: 8692-15), 10 - 14 March 2013.

[20] Li Y., Li J. and Li W., Experimental investigation on an adaptive magnetorheological elastomer base isolator, 2013 IEEE/ASME International Conference on Advanced Intelligent Mechatronics (AIM 2013), Pages381-386, Wollongong, Australia, July 9 - 12, 2013,

[21] Li Y., Li J., Tian T. and Li W., A highly adjustable magnetorheological elastomer base isolator for applications on real-time adaptive control, Smart Materials and Structures, 22(9): 095020. 2013.

[22]Yang J., Du H., Li W., Li Y., Li J., Sun, S. and Deng H., Experimental study and modeling of a novel magnetorheological elastomer isolator, Smart Materials and Structures, 22(11): 117001, 2013,

[23] Li Y. and Li J., A highly-adjustable base isolator utilizing magnetorheological elastomer: experimental testing and modeling, submitted to ASME Journal of Vibration and Acoustics. 2014

[24] Li Y., Li J. and Li Y., Adaptive MRE vibration isolation assembly and system, Australian PCT Patent, Patent No. 2012904337

[25] Jiang X., Li Y. and Li J., 'A piezoelectric-waferstack vibration energy harvester for wireless sensor networks', the SPIE 20th Annual International Symposium on Smart Structures and Materials + Nondestructive Evaluation and Health Monitoring, Town \& Country Resort and Convention Center, San Diego, California, United States (Paper ID: 8692148), 10 - 14 March 2013.

[26] Jiang X., Li Y. and Li J., A novel piezoelectricwafer-stack vibration energy harvester, 22nd Australasian Conference on the Mechanics of Structures and Materials, pages 399-404, Sydney, Australia, 11-14 December, 2012.

[27] Jiang X., Wang J., Li Y. and Li J., Design and modeling of a novel tubular linear permanent magnet vibration energy harvesting system, International Journal of Applied Electromagnetics and Mechanics, Doi: 10.3233/JAE- 141769, 2014.

[28] Jiang X., Li Y. and Li J., Design of a novel linear permanent magnet vibration energy harvester', 2013 IEEE/ASME International Conference on Advanced Intelligent Mechatronics (AIM 2013), Pages 10901095, Wollongong, Australia, July 9 - 12, 2013.

[29] Nguyen M. T., Kwok N. M., Ha Q .P., Li J. and Samali B., Optimal Placement of Dampers for Building Semi-Active Control using an Efficient Multi-objective Binary Genetic Algorithm, Intl. Symposium on Automation and Robotics in Construction (ISARC2007), Kochi (Cochin), Kerala, India.

[30] Askari, M., Li, J. and Samali, B. A Multi-objective Subtractive FCM Based TSK Fuzzy System with
Input Selection, and Its Application to Dynamic Inverse Modelling of MR Dampers, Artificial Intelligence and Soft Computing, Lecture Notes in Computer Science, 7894: 215-226, 2013

[31]M Askari, Multi Objective Optimal Placement of Structural Control Actuators, 6th Australasian Congress on Applied Mechanics (ACAM 6), Pages 1148-1157,Perth, Australia, December 2010.

[32] Nguyen M. T., Kwok N. M., Ha Q .P., Li J. and Samali B., "Mitigation of Seismic Responses in Building Structures using Magneto-rheological Dampers," Intl. Symposium on Automation and Robotics in Construction (ISARC2007), Kochi (Cochin), Kerala, India.

[33] Kwok N. M., Ha Q. P., Li J. and Samali B. BoucWen model parameter identification for a MRF damper using computationally efficient GA, ISA Transactions, 46(2):167-179, 2007.

[34] Kwok N. M., Ha Q. P., Nguyen T.H., Li J. and Samali B. A novel hysteretic model for magnetorheological fluid dampers and parameter identification using particle swarm optimization, Sensors \& Actuators: A. Physical, 132(2):441-451, 2006.

[35]Hong S. M., Nguyen M. T., Kwok N. M., Ha Q. P. and Li J. Hysteretic model for magnetorheological fluid dampers using a curve fitting approach, Japanese Society of Applied Electromagnetics and Mechanics(Special Issue to the Asia-Pacific Symposium on Applied Electromagnetics and Mechanics), 15: S176-S179, 2007.

[36]Nguyen T. H., Kwok N. M., Ha Q .P., Li J. and Samali B., Adaptive Sliding Mode Control for Civil Structures using Magnetorheological dampers," Proc. Int. Sym. Automation and Robotics in Construction, Pages 636-641, Tokyo, Japan, 3-5 Oct., 2006.

[37]Ha, Q. P., Kwok, N. M., Nguyen, M. T., Li, J., and Samali, B. Mitigation of Seismic Responses on Building Structures Using MR Dampers with Lyapunov-Based Control, Structural Control and Health Monitoring, 15(4): 604-621, 2008.

[38] Ha, Q.P., Nguyen, M.T., Li, J. and Kwok, N.M. Smart Structures With Current-Driven MR Dampers: Modeling and Second-Order Sliding Mode Control, IEEE/ASME Transactions on Mechatronics, 18(6): 1702-1712, 2013

[39]Askari M., Li J. and Samali B, 2012, A Novel FRFBased Damage Detection Method Utilising Wavelet Decomposition, $22^{\text {nd }}$ Australasian Conference on the Mechanics of Structures and Materials (ACMSM22), Sydney, Australia, December 11-14, 2012.

[40] Askari M., Li J. and Samali B, Application of extended, unscented, iterated extended and iterated unscented Kalman Filter for real-time structural identification, 7th Australasian Congress on Applied Mechanics, ACAM 7, pages 1041-1050,Adelaide, Australia, 9-12 December 2012.

[41] Askari M., Li J. and Samali B, Adaptive multiple forgetting factor recursive least square (AMFF-RLS) for real-time structural identification with unknown 
input, 7th Australasian Congress on Applied Mechanics, ACAM 7, pages 1052-1061, Adelaide, Australia, 9-12 December 2012.

[42]Askari, M., Li, J. and Samali, B. Adaptive multiple forgetting factor recursive least square (AMFF-RLS) for real-time structural identification, $22^{\text {nd }}$ Australasian Conference on the Mechanics of Structures and Materials (ACMSM22), pages 879-
884Sydney, Australia, December 11-14, 2012.

[43] M Askari, A H Markazi, A new evolving compact optimised Takagi-Sugeno fuzzy model and its application to nonlinear system identification, International Journal of Systems Science, 43(4):77685, 2012. 